1 Evans PA, Farnell RD, Moanlypour S, McKeever JA. Thrower's fracture: a comparison of two presentations of a rare fracture. F Accid Emerg Med 1995;12:222-4.

2 Tullos HS, King JW. Throwing fractures in sports. Orthop Clin North Am 1983;4:709-20.

3 Lahoti OP, Callanan I, Reidy DP, Kelly EP McElwain JP. Elbow fractures and carpa injuries. F Hand Surg 1995;20B:620-2.

\section{Nurse practitioners}

EDITOR,-Freij et al have shown that nurse practitioners are as good as senior house officers at deciding which minor trauma patients should be $x$ rayed and whether those $x$ rays show a fracture. ${ }^{1}$ Unfortunately there is a lot more to the management of these patients than the requesting and interpretation of $x$ rays.

In particular their correct management often requires a detailed knowledge of anatomy, physiology, pathology, and pharmacology. In addition about $15 \%$ of these patients will have a coincidental medical condition which will often affect the management of their injury. ${ }^{2}$ Others will have social circumstances that must be considered. It is therefore clear that only medical practitioners have sufficient training to manage minor trauma patients properly. Freij's findings lead us nowhere.
1 Freij $\mathrm{R}$ M, Duffy $\mathrm{T}$, Hackett $\mathrm{D}$, et al. Radiographic interpretation by nurse pracRadiographic interpretation by nurse prac-
titioners in a minor injuries unit. $f$ Accid titioners in a minor injurie
Emerg Med 1996;13:41-3.

2 Leaman A. Walking wounded patients - how much history is necessary? Br $\mathfrak{f}$ Accid Emerg Med 1986;1:12.

\section{An unusual site to find a "swallowed"} foreign body

EDITOR,-A 43 year old DIY enthusiast presented to casualty complaining that he swallowed a nail he had been holding between his teeth, which he felt had lodged at the back of his throat. He had made himself gag several times without any improvement in his symptoms. Oropharyngeal examination and indirect laryngoscopy were unremarkable. However, the lateral neck radiograph showed the nail lying on the floor of the nose (see the figure).

Impacted foreign bodies are most commonly found in the tonsillar area, and only $25 \%$ of foreign bodies impact below the hypopharynx. Symptoms are notoriously unreliable at predicting whether a foreign body is actually present. In this case his forced gagging had pesumably regurgitated the nail through the choana, and the nail was removed uneventfully.

$$
\begin{array}{r}
\text { Malcolm Hilton } \\
\text { Accident and Emergency Department, }
\end{array}
$$
Frenchay Hospital, Bristol

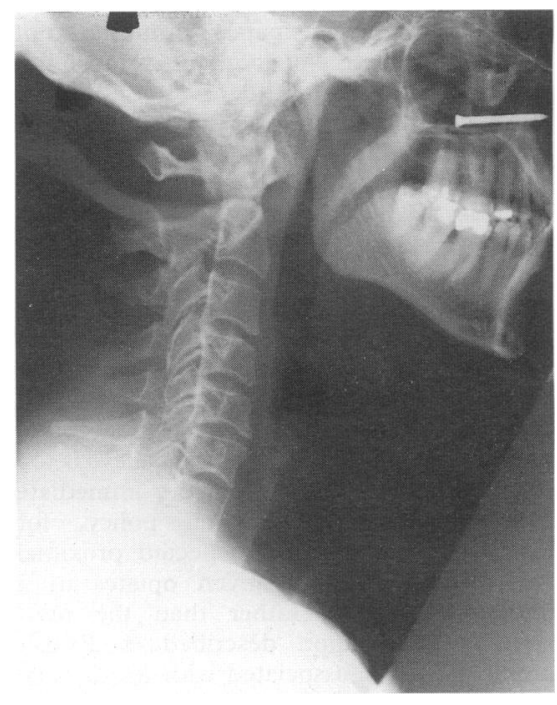

